\title{
Influence of Simulated Acid Rain Corrosion on the Uniaxial Tensile Mechanical Properties of Concrete
}

\author{
Ying-zi Zhang, ${ }^{1}$ Ying-fang Fan, ${ }^{2}$ and Hong-nan $\mathrm{Li}^{3}$ \\ ${ }^{1}$ Department of Civil Engineering, Harbin Institute of Technology, Weihai, Shandong 264209, China \\ ${ }^{2}$ Institute of Road and Bridge Engineering, Dalian Maritime University, Dalian, Liaoning 116026, China \\ ${ }^{3}$ State Key Laboratory of Coastal and Offshore Engineering, Dalian University of Technology, Dalian, Liaoning 116023, China
}

Correspondence should be addressed to Ying-fang Fan, fanyf72@yahoo.com.cn

Received 5 March 2012; Accepted 7 May 2012

Academic Editor: Facundo Almeraya

Copyright (c) 2012 Ying-zi Zhang et al. This is an open access article distributed under the Creative Commons Attribution License, which permits unrestricted use, distribution, and reproduction in any medium, provided the original work is properly cited.

\begin{abstract}
An experimental study on the uniaxial tensile property of concrete exposed to the acid rain environment was carried out. Acid rain with $\mathrm{pH}$ level of 1.0 was deposed by the mixture of sulfate and nitric acid solution in the laboratory. Dumbbell-shaped concrete specimens were immersed in the simulated acid rain completely. After being exposed to the deposed mixture for a certain period, uniaxial tensile test was performed on the concrete specimens. The results indicate that elastic modulus, tensile strength, and peak strain have a slight increase at the initial corrosion stage, and with the extension of corrosion process, elastic modulus and tensile strength decrease gradually, while the peak strain still increases. It is found that the compressive strength is more sensitive than the tensile strength in aggressive environment. Based on the experimental results, an equation was proposed to describe the ascending branch of the stress-strain curve of the concrete corroded by acid rain.
\end{abstract}

\section{Introduction}

Acid rain has become an issue of widespread concern in Asia, and it was first recognized as a potential environmental pollution problem in the late 1970s and early 1980s. It was also an increasing problem in China during the last decades [1-4]; one third of China's land mass was affected by acid rain. The acid rain is composed of acid substances, such as $\mathrm{H}_{2} \mathrm{SO}_{4}, \mathrm{HCl}$, and $\mathrm{HNO}_{3}$, which readily react with $\mathrm{Ca}(\mathrm{OH})_{2}$ and form $\mathrm{CaSO}_{4} \cdot 2 \mathrm{H}_{2} \mathrm{O}, \mathrm{Ca}\left(\mathrm{NO}_{3}\right)_{2} \cdot 4 \mathrm{H}_{2} \mathrm{O}$, and $\mathrm{CaCl}_{2} \cdot 6 \mathrm{H}_{2} \mathrm{O}$. Because the solubility of these products is higher than that of $\mathrm{CaCO}_{3}$, which is formed at the surface by the reaction of $\mathrm{Ca}(\mathrm{OH})_{2}$ with $\mathrm{CO}_{2}$ (carbonation), they are dissolved in rainwater and penetrate into the inner pores of concrete. After the evaporation of rainwater, these salts redeposit and give rise to stress in the concrete structure, resulting in cracking, mass loss, and eventually structural failure. In the early 1950s, US Environmental Protection Agency reported that the cost of repairing or replacing the concrete structure every year due to acid rain in the United States was more than $\$ 5$ billion dollars. In Britain, the economic loss due to acid rain was $0.15 \%$ of the GNP. Guo [5] in 2001 estimated that the direct material loss due to acid rain only in Guangzhou was 1.2 billion Chinese Yuan. Although some ways have been used to reduce acid rain, the acid rain region in China even continue to expand, therefore, the property of the corroded concrete have become to be a critical issue and attracted a lot of researchers worldwide [6-12]. However, due to the complicated mechanism, there remains only very limited available literature on the tensile property of concrete corroded by acid rain. In this paper, acid rain was simulated in the laboratory, a series of C30 dumbbell-shaped specimen and the accompanying specimens were exposed to different simulated aggressive environments for different periods. A series of tests, including weighing, compressive tests, and tensile tests were conducted at different conditioned stages to determine mass loss, compressive strength, and tensile properties.

\section{Experimental Details}

2.1. Materials and Specimen Preparation. C30 concrete was applied to cast the specimen. The dosage of the concrete is shown in Table 1 . The specimens for tension test were 
TABLE 1: Mix proportion of the concrete.

\begin{tabular}{lcccc}
\hline Cement $/ \mathrm{kg}$ & Sand $/ \mathrm{kg}$ & Pebble $/ \mathrm{kg}$ & Water $/ \mathrm{kg}$ & Sand ratio $/ \%$ \\
\hline 450 & 541 & 1200 & 200 & 31 \\
\hline
\end{tabular}

dumbbell-shaped, as shown in Figure 1 and the accompanying specimens were cubic, $100 \mathrm{~mm}$ in length, which were used to measure the compressive strength.

2.2. Accelerate Corrosion Technique. Concrete is subjected to a variety of exposure conditions, such as frequency of drying and wetting cycles, different temperatures, superficial carbonation, and drying shrinkage. All the conditions will affect the mode of attack. Therefore, it is difficult to exactly duplicate the field attack condition in the laboratory. Though the field corrosion test can better simulate the actual corrosion process, it always took much more time to fulfill the corrosion. Therefore, the accelerate corrosion test is applied in this paper. Wang et al. [13] pointed out that the acid rain is due to sulfuric-acid in most parts of China. Therefore, only sulfuric acid type acid rain is simulated in this study, which was achieved by mixing sulfate and nitric acid solutions with $\mathrm{pH}$ value of 1.0 , and the specimens were divided into several groups in the different corrosion time, the corrosion conditions are listed in Table 2 in detail.

2.3. Test Device and Procedure. Liu [14] used site and accelerate tests to study the concrete corrosivity, it was found that the results showed a good coincidence in two different exposure conditions. Obviously, the submerging method is more suitable for cement concrete, therefore, it is adopted for accelerated test in this study. After being cured in a fog room for 28 days, the specimens were naturally cured in the laboratory for 120 days, and then they are placed in the anticorrosion bucket containing simulated acid salutation (Figure 2). Since $\mathrm{pH}$ values of the solutions were changing as the conditioning continued, the acidity of solution was recorded by PB-10 Sartorius Acidometer every day, acid was added to the solution periodically and mixed well with the solution so that a constant $\mathrm{pH}$ value was guaranteed. After being corroded for different exposure periods, a group of 3 specimens will be picked out to be dried for about 5 days, followed by visual inspection, weighting, compressive tests, tensile tests, to determine mass loss, compressive strength, tensile strength, and elastic modulus, respectively. The compressive test was carried out on an electrohydraulic servocompressive testing system (YAW-YAW2000A, Figure 3) with a capacity of $2000 \mathrm{kN}$. Following present Chinese code for concrete compressive testing (GB/T50081-2002) [15], the loading rate was $0.3 \mathrm{MPa} / \mathrm{s}$. The tensile tests were carried out on the MTS810 electro-hydraulic dynamic-static universal testing machine. The MTS810 machine is a programmable displacement controlled loading system and can produce tensile and compressive loads at a maximum nominal rate up to $150 \mathrm{~mm} / \mathrm{s}$. Its force capacity is $100 \mathrm{kN}$ and stiffness is $2.6 \times 10^{8} \mathrm{~N} / \mathrm{s}$. The measurement system consists of DPM$8 \mathrm{H}$ strain amplifier, INV306D intelligent signal processor, and DASP software. The highest frequency of MTS810 can

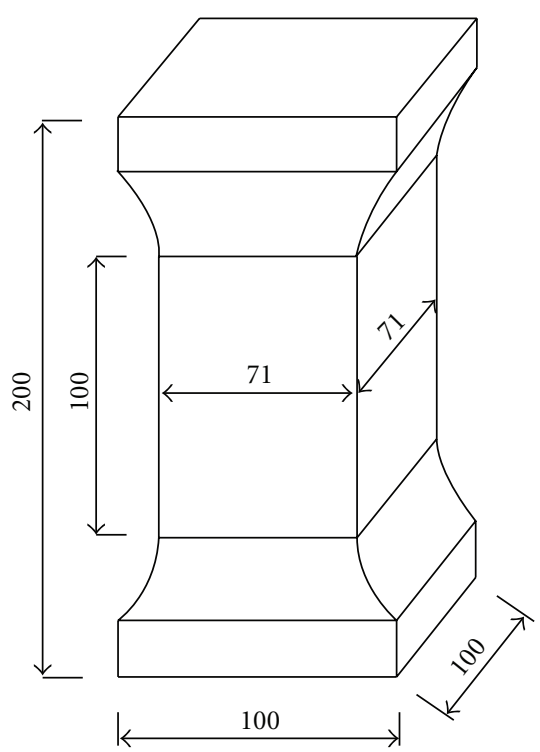

Figure 1: Dimensions of dumbbell-shaped specimen (unit: $\mathrm{mm}$ ).

reach $10^{4} \mathrm{~Hz}$. The machine can offer different strain rates, strain rate of $10^{-5} / \mathrm{s}$ is applied in this test. Foil strain gauges, $50 \mathrm{~mm}$ in length and $5 \mathrm{~mm}$ in width, were used to measure strain histories during tensile process. Twocrossed strain gauges were glued onto the middle of each side of specimen to measure the longitudinal and lateral strains respectively (Figure 4). In addition, the linear variable differential transformer (LVDT) was fixed on the specimens to measure the displacement after the appearance of cracks. The load device and instrument arrangement are shown in Figure 5.

\section{Results and Discussion}

Uniaxial tensile tests were carried out on the dumbbellshaped specimens. For multiple reasons, such as the randomicity, diversity, and complexity of distribution of concrete, and the limited capacity of the testing system, testing equipments, testing techniques, and so on, the center of each cross-section tensile strength of specimen is not the same location, therefore, no method could make the test specimen achieve the perfect axial tensile state, and these may be influence the accuracy of the test results. The 25 tensile specimens were achieved ideal results.

3.1. Visual Observations. During the test, specimen were picked out at the assignment time for visual inspection. From Figure 6, it is found that the concrete surface became unsmooth with the increase of the corrosion time, up to 33 days, the surface became to be honeycomb, large amounts of coarse aggregates can be seen, and concrete at the specimens became to be powdery, and the surface colour is similiar to what was observed by Xie [12] and Fan et al. [16].

3.2. Mass Change. During the test, specimens were periodically picked out from the simulated acid rain for visual 
TABLE 2: Experimental conditions.

\begin{tabular}{lcccc}
\hline Specimen C30 & Designation & Exposing condition & Number of specimen & Immersion time (days) \\
\hline Dumbbell-shaped specimens & $\begin{array}{c}\mathrm{H}_{2} \mathrm{SO}_{4}+\mathrm{HNO}_{3} \\
(\text { molar ratio is 9: } 1)\end{array}$ & $\mathrm{pH} 1.0$ & $4 \times 10$ & $0,5,11,15,18,21,24,27,30,33$ \\
Cube specimens & $\begin{array}{c}\mathrm{H}_{2} \mathrm{SO}_{4}+\mathrm{HNO}_{3} \\
(\text { molar ratio is 9: } 1)\end{array}$ & $\mathrm{pH} 1.0$ & $3 \times 10$ & $0,5,11,15,18,21,24,27,30,33$ \\
\hline
\end{tabular}

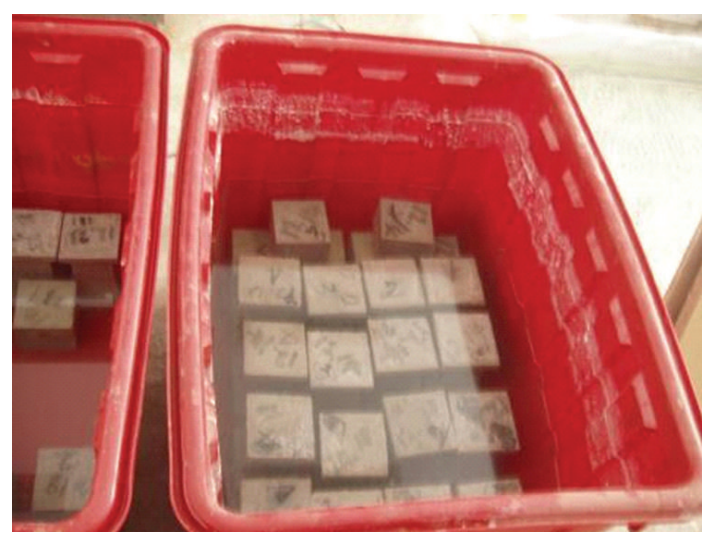

Figure 2: Concrete specimens exposed to the similated acid rain.

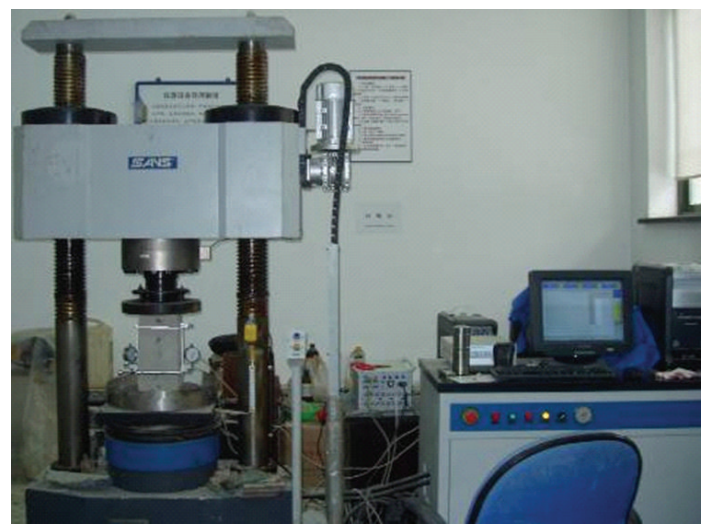

FIGURE 3: Electrohydraulic servo testing system.

inspection. It was observed that the surface of the concrete changed became very rough, honeycomb voids were formed, and coarse aggregates were exposed, this caused the specimen's mass change. Mass change versus corrosion time for the specimens is shown in Figure 7. It can be seen that mass of cube specimens and dumbbell-shaped specimens all first increase and then decrease with the increasing of corrosion duration, which is similar to the results obtained by the literature [16].

3.3. Tensile Strength and Compressive Strength. During the tensile test, it was found that a number of coarse aggregates were broken in the short corrosion time (such as day 5 and day 11), the fracture surface of the specimen mainly passes through the aggregate and the aggregate-mortar interfaces, the fracture of the specimen became flattened with the

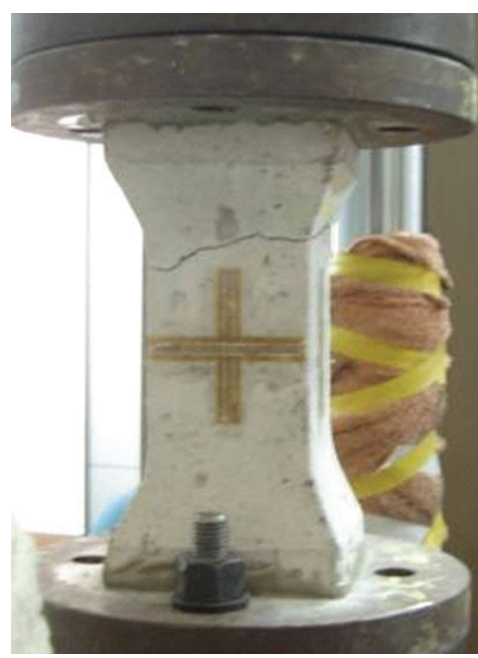

FIGURE 4: Arrangements of strain gages of on the tensile specimen.

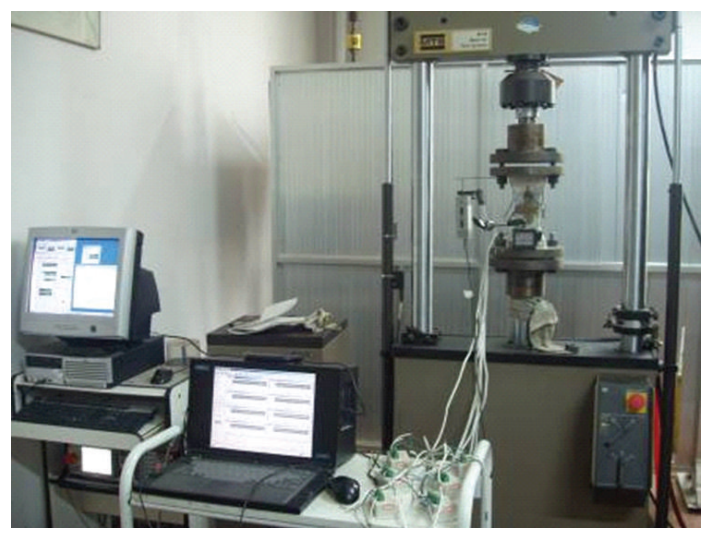

FIGURE 5: MTS810 Electrohydraulic dynamic-static universal testing machine.

increasing corrosion duration, it can be inferred that dense degree between the aggregate and mortar had a slight increase, therefore, the tensile strength became larger than that of the no-corrosion specimen (see Table 2), however, the fracture surface failure modes were mainly coarse aggregates bond failure for severe deterioration (day 33), typical modes of which are depicted in Figure 8. Strength of concrete exposed to acid solution for different periods were listed in Table 3 in detail.

To quantify the deterioration in tensile and compressive strength of corroded concrete, the strength degradation 


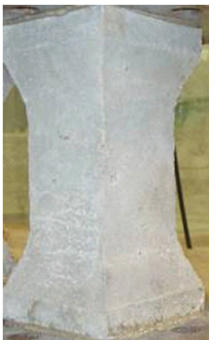

(a) $0 \mathrm{~d}$

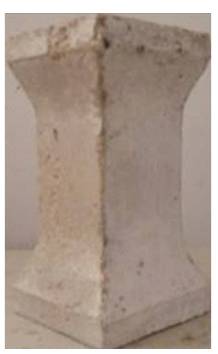

(b) $15 \mathrm{~d}$

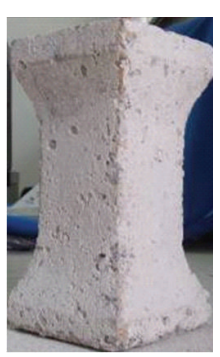

(c) $24 \mathrm{~d}$

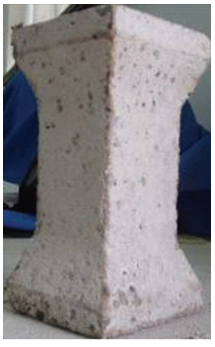

(d) $27 \mathrm{~d}$

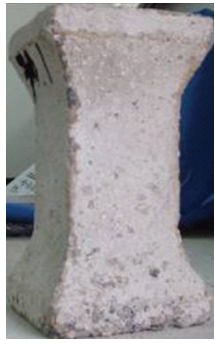

(e) $30 \mathrm{~d}$

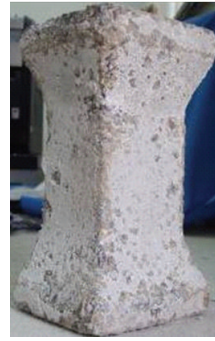

(f) $33 \mathrm{~d}$

FIgURE 6: Surface description of the concrete specimens corroded for different period.

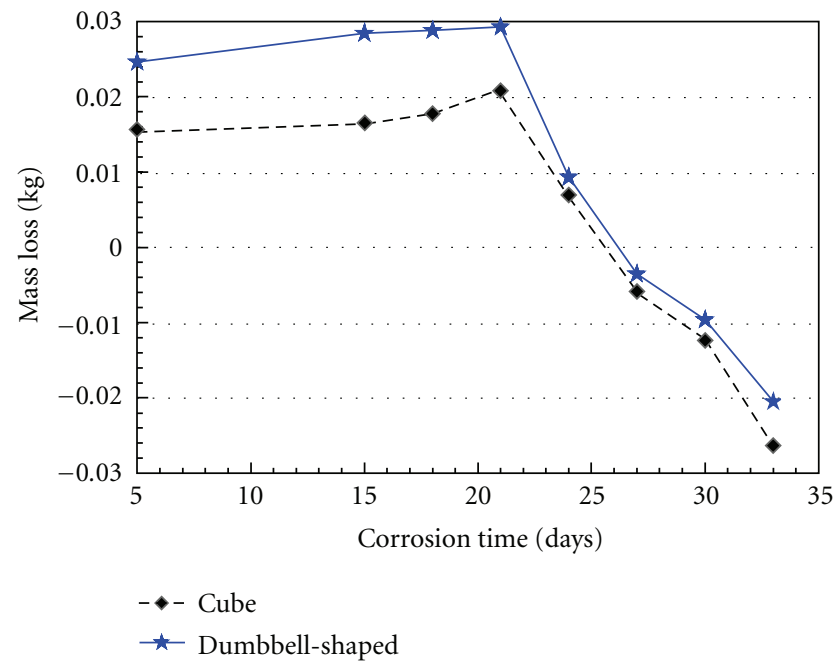

Figure 7: Relation between mass loss and corrosion duration.

ratio $D_{\mathrm{fc}}$ and $D_{\mathrm{ft}}$ are introduced. The degradation ratio are expressed as follows:

$$
\begin{aligned}
& D_{\mathrm{fc}}=\left(1-\frac{f_{\mathrm{ct}}}{f_{\mathrm{c} 0}}\right) \times 100 \%, \\
& D_{\mathrm{ft}}=\left(1-\frac{f_{\mathrm{ct} t}}{f_{\mathrm{ct} 0}}\right) \times 100 \%,
\end{aligned}
$$

where $D_{\mathrm{fc}}$ and $D_{\mathrm{ft}}$ are the degradation ratio of corroded concrete, $f_{\mathrm{c} 0}$ is the tensile strength of uncorroded specimen, $f_{\text {ct }}$ is the tensile strength of specimen exposed to the acid solution for $t$ days, $f_{\text {cto } 0}$ is defined as the compressive strength of uncorroded specimen, and $f_{\mathrm{ctt}}$ is the compressive strength of specimen exposed to the acid solution for $t$ days. Based on the testing results, relation between strength loss and immersion time is shown in Figure 9. From Figure 9, it can be seen that the strength $D_{\mathrm{fc}}$ and $D_{\mathrm{ft}}$ decreases and then increases as conditioning continue, but their critical time is different. The critical value of the compressive strength degradation ratio is larger than that of the tensile strength degradation ratio, and $D_{\mathrm{fc}}$ showed greater decline than $D_{\mathrm{ft}}$, this indicates that the compressive strength is more sensitive to aggressive environment than the tensile strength, but this conclusion needs to be further validated due to limited number of specimens in this paper.

3.4. Elastic Modulus. The modulus of elasticity is calculated a secant modulus in this paper, a secant modulus is calculated from the origin to a defined point on the stress-strain curve, usually within $40 \%$ to $60 \%$ of the sample's ultimate strength [17]. In this study, the elastic modulus was measured $50 \%$ the specimen's ultimate strength. Form the experiment result, the elastic modulus at different corrosion period is reported in Table 4. As can be seen from Table 4, elastic modulus exist some random fluctuation during the test.

To quantify the deterioration in elastic modulus of corroded concrete, the degradation ratio $D_{E c t}$ is introduced. The degradation ratio are expressed as follows:

$$
D_{E \mathrm{ct}}=\left(1-\frac{E_{\mathrm{ct}}}{E_{\mathrm{c} 0}}\right) \times 100 \%,
$$

where $D_{E \mathrm{ct}}$ is the degradation ratio of corroded concrete; $E_{\mathrm{c} 0}$ is the elastic modulus of uncorroded specimen; $E_{\mathrm{ct}}$ is the elastic modulus of specimen exposed to the acid solution for $t$ days. Relation between elastic modulus loss and corrosion duration is shown in Figure 10. It can be seen that elastic modulus of the specimens are unstable during the tensile test, the same tendency can be observed on $D_{\mathrm{Ec}}$ for specimens exposed to the three solutions in literature [16]. There may be several reasons: (a) some construction variances during casting; (b) the surface of the specimen became unflattered with the increasing corrosion duration, this influenced the strain gauge paste and date acquisition; (c) There are personal errors, system error, and random error and so on; (d) the limited number of the specimens. However, the $D_{E c t}$ has a slight decrease at initial stage (day 5 ) and then fluctuates increasingly when the conditioning continues, it means that the elastic modulus of the tensile specimens decreases when the increasing of corrosion duration.

The elastic modulus of corroded specimens is calculated by (5) proposed in the literature [18], which depended mainly on the fresh elastic modulus, poisson ratio, and void volume before and after corrosion. As can be seen from Table 4, few model calculation results have good agreement with the experimental results. The following reasons exist: (1) some construction variances during casting and conditioning process; (2) the personal error during the test; (3) there is only one control specimen during the 


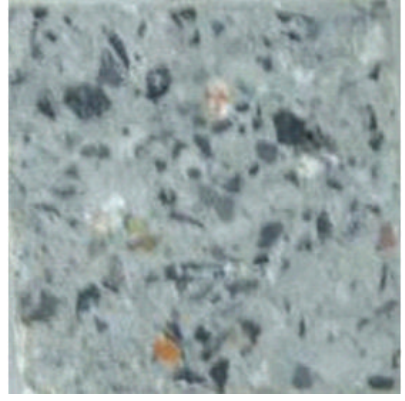

(a) $5 \mathrm{~d}$

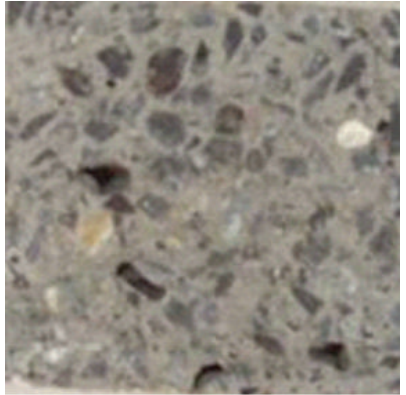

(b) $11 \mathrm{~d}$

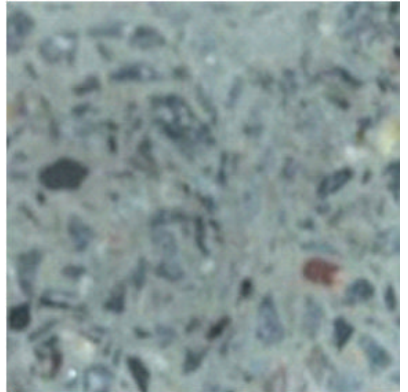

(c) $21 \mathrm{~d}$

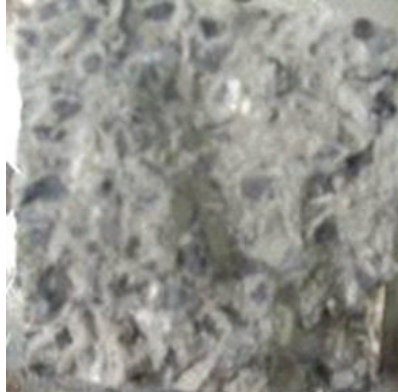

(d) $33 \mathrm{~d}$

FIgURE 8: Typical fracture area of concrete in different corrosion period.

TABLE 3: Strength of concrete exposed to acid solution for different periods.

\begin{tabular}{|c|c|c|c|c|c|c|c|c|c|c|}
\hline Immersion time/days & 0 & 5 & 11 & 15 & 18 & 21 & 24 & 27 & 30 & 33 \\
\hline Tensile strength/MPa & 2.738 & 2.915 & 2.938 & 2.946 & 2.837 & 2.704 & 2.698 & 2.702 & 2.676 & 1.727 \\
\hline Compressive strength/MPa & 42.746 & 44.240 & 44.758 & 35.835 & 35.475 & 32.106 & 34.342 & 34.329 & 34.309 & 30.847 \\
\hline
\end{tabular}

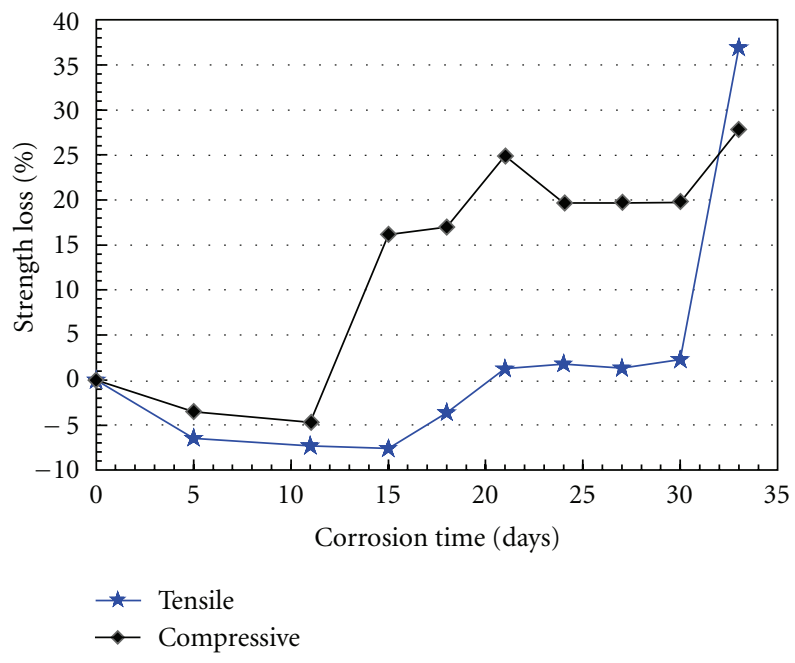

FIGURE 9: Relation between strength and corrosion time.

different corrosion time, however, the elastic modulus of concrete may change at different time; (4) specimen number is not enough; (5) there is a little volume expansion in this high simulated acid solutions.

3.5. Peak Strain. Peak strain is defined as the strain when the tensile stress reaches the maximum stress during the test in this paper. To quantify the deterioration in peak strain of corroded concrete, and the degradation ratio $D_{\mathcal{E} c}$ is introduced in the following:

$$
D_{\varepsilon c}=\left(1-\frac{\varepsilon_{\mathrm{ct}}}{\varepsilon_{\mathrm{c} 0}}\right) \times 100 \%,
$$

where $D_{\varepsilon c}$ denotes the degradation ratio of corroded concrete, $\varepsilon_{\mathrm{c} 0}$ is the strain of uncorroded specimen, and $\varepsilon_{\mathrm{ct}}$ is the strain of specimen exposed to the acid solution for $t$ days. Relation between peak strain loss and corrosion duration is shown in Figure 11. It is shown that the peak strain of the specimens exposed to acid solutions will decrease with exposure days linearly (correlation coefficient is 0.916). It is obvious that the degree of corrosion damage increases with exposure time.

3.6. Stress-Strain Relation. During the tensile tests, we found that once the peak strain is reached, a visible crack will appear and specimens will fail subsequently in a very short time. Many reasons, such as some construction variances during casting, conditioning process, and impossibility of the perfect axial tensile state, lead to obtain the descending part of the stress-strain curve is difficult, therefore, only the ascending branch of the stress-strain curve will be discussed in this study. Typical stress-strain curves of concrete corroded by acid solutions were recorded in the experiment, which are plotted, respectively, in Figure 12.

From Figure 12, it can be seen that the changing trends in tension strain-stress relation for concrete corroded with different concentration are similar. At the initial stage (not exceeding 11 days), the 3 major mechanical property indexes, uniaxial tensile strength, peak strain, and elastic modulus increase gradually, with the increasing of corrosion duration, the uniaxial tensile strength and elastic modulus decrease, but the peak strain continues to increase, which shows that the damage increases with the corrosion duration.

In order to describe the ascending branch of stress-strain curves of tensile concrete specimen in different corrosion periods, a formula is presented which is based on the current Chinese concrete structure design code (GB/T 50010_2002) [15].

Firstly, the dimensionless form of the stress and the strain are obtained

$$
x=\frac{\varepsilon}{\varepsilon_{t}}, \quad y=\frac{\sigma}{f_{t}},
$$

where $f_{t}$ is the uniaxial tensile strength of concrete, $\varepsilon_{t}$ is the peak strain of the concrete specimen. 
TABLe 4: Experimental data and model calculation results.

\begin{tabular}{|c|c|c|c|c|c|c|c|c|c|c|}
\hline Immersion time/days & 0 & 5 & 11 & 15 & 18 & 21 & 24 & 27 & 30 & 33 \\
\hline Test results $/ 10^{3} \mathrm{MPa}$ & 34.4 & 41.6 & 35.7 & 28.9 & 22.7 & 20.0 & 26.0 & 39.3 & 22.6 & 40.9 \\
\hline Model calculation results $/ 10^{3} \mathrm{MPa}$ & 34.4 & 35.0 & 35.6 & 35.1 & 35.0 & 35.1 & 34.6 & 34.3 & 34.2 & 33.9 \\
\hline Error/\% & 0 & 18.9 & 0.28 & 17.7 & 35.2 & 43.1 & 24.9 & 14.6 & 33.9 & 20.6 \\
\hline
\end{tabular}

Note: error $=100 \% \times \mid$ testresults - calculatedresults $\mid$.

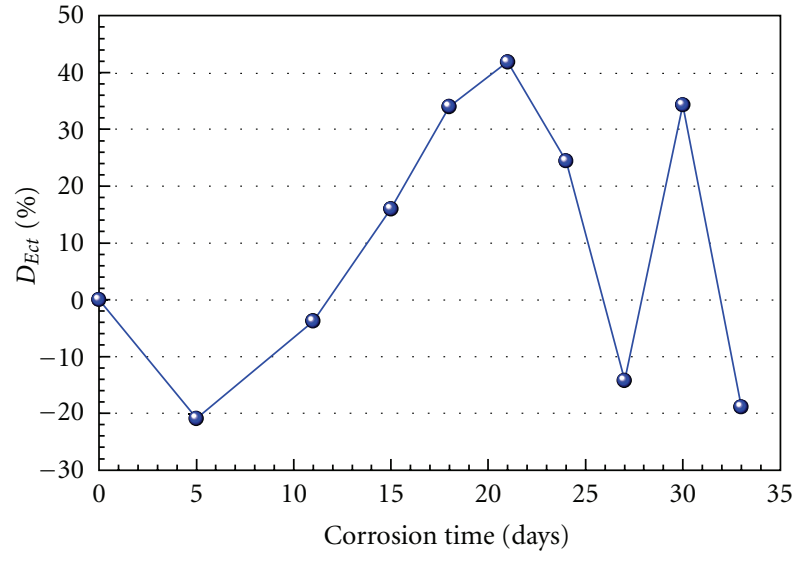

Figure 10: Relation between elastic modulus loss and corrosion duration.

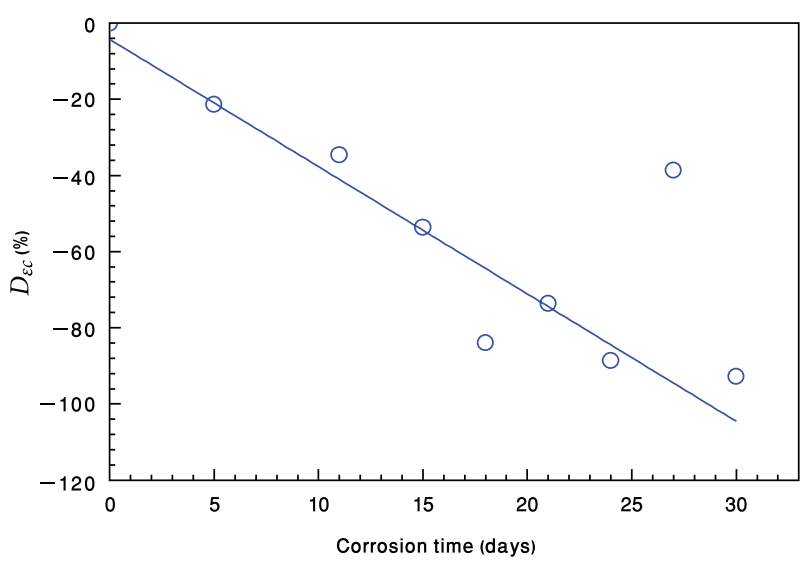

Figure 11: Relation between deterioration ratio of peak stain and corrosion duration.

Therefore, the equation, which describes the ascending branch of stress-strain curves $(x \leq 1)$ of tensile concrete specimen, can be written

$$
y=A x+B x^{m},
$$

where $A$ and $B$ are polynomial coefficients, $m$ is exponent of polynomial, which all can be obtained from the experiment. By fitting to the test data in this study, (6) can be obtained, where the correlation coefficient $R^{2}=0.97$. From Figure 13, it is indicated that the polynomial function can better describe the ascending branch of tensile stress-strain curves of concrete corroded by the acid rain,

$$
y=1.15 x-0.13 x^{2}
$$

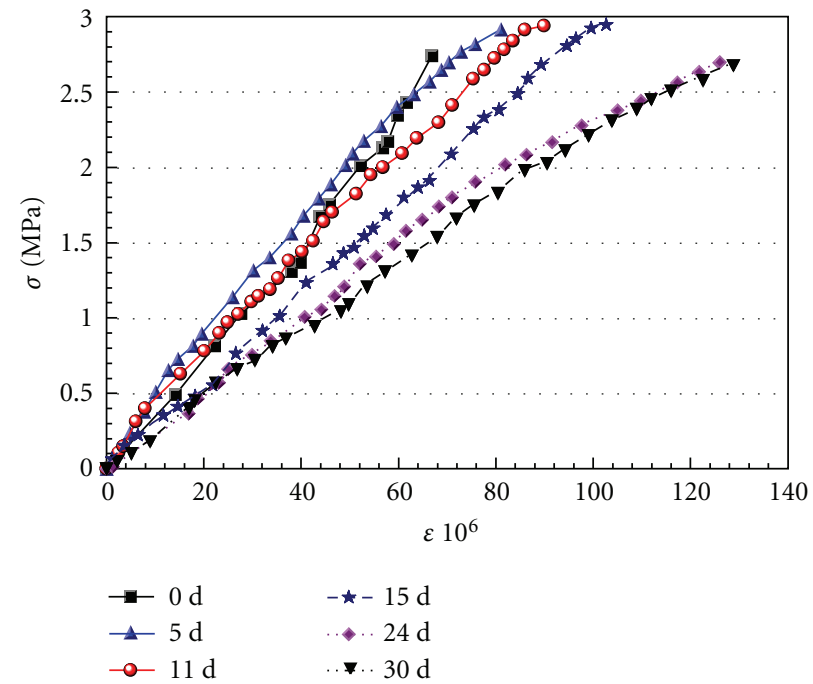

FIGURE 12: Ascending branch of stress-strain curves of concrete specimen corroded for different periods.

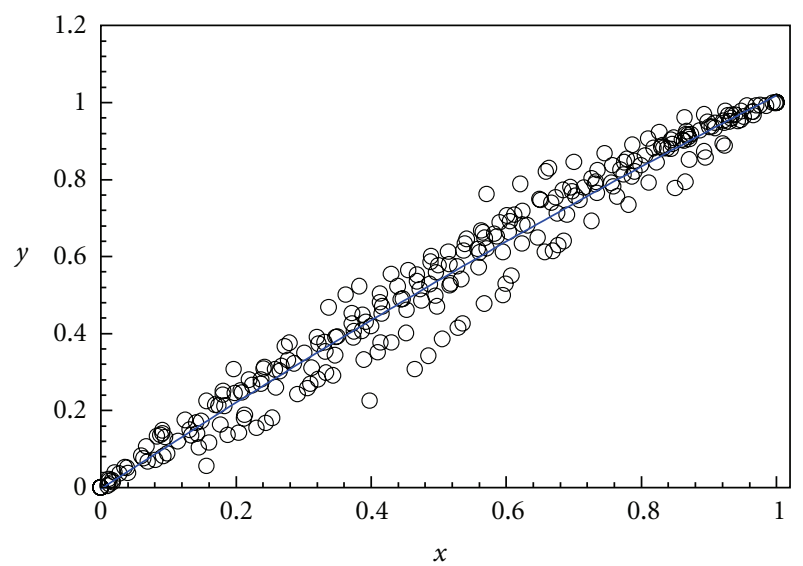

FIGURE 13: Ascending branch of stress-strain curves of corroded concrete specimen.

\section{Conclusion}

In order to investigate the tensile properties of the concrete corroded by the acid rain, laboratory accelerating tests were performed on C30 specimen, acid solution $\mathrm{pH} 1.0$ was used as the corrosive medium herein. Based on the testing results, following conclusions can be drawn

(1) At the initial stage, the tensile strength of deteriorated specimens increases slightly, and then decreased 
gradually, and the compressive strength is more sensitive to aggressive environment than the tensile strength.

(2) When the immersing period does not exceed 11 days, the 3 major mechanical property indexes, uniaxial tensile strength, peak strain and elastic modulus increase gradually, however, when the corrosion time exceeds 15 days, with the increasing of corrosion duration, the uniaxial tensile strength and elastic modulus decrease, while the peak strain still increases which shows that the damage increases with the corrosion duration.

(3) A polynomial model, which can describe the ascending branch of stress-strain curves of tensile concrete specimen corroded by acid rain in different periods, is proposed.

\section{Acknowledgments}

This paper is funded by the National Natural Science Foundation of China (Grant no. 50708010 and Grant no. 51178069), National Basic Research Program of China (no. 2011CB013605), Liaoning Provincial Funded project (Grant no. 20092149), and supported by the Fundamental Research Funds for the Central Universities.

\section{References}

[1] T. Larssen, H. M. Seip, A. Semb et al., "Acid deposition and its effects in China: an overview," Environmental Science \& Policy, vol. 2, no. 1, pp. 9-24, 1999.

[2] X. M. Zhang, F. H. Chai, S. L. Wang, X. Z. Sun, and M. Han, "Research progress of acid precipitation in China," Research of Environmental Sciences, vol. 23, no. 5, pp. 527-531, 2010 (Chinese).

[3] Q. Hou, Y. X. Zhao, and X. B. Xu, "Spatial-temporal distribution of acid rain in china during 2005," Advance in Climate Change Research, vol. 2, no. 5, pp. 242-245, 2006 (Chinese).

[4] Q. Hou and Y. X. Zhao, "An analysis on characteristics of regional acid rain over China in 2007," Advance in Climate Change Research, vol. 5, no. 1, pp. 7-11, 2009 (Chinese).

[5] J. Guo, Economic Loss Estimation on the Material Damage Caused by the Acid Deposition, Beijing University of Chemical Technology, BeiJing, China, 2004.

[6] H. Okochi, H. Kameda, S. I. Hasegawa, N. Saito, K. Kubota, and M. Igawa, "Deterioration of concrete structures by acid deposition-an assessment of the role of rainwater on deterioration by laboratory and field exposure experiments using mortar specimens," Atmospheric Environment, vol. 34, no. 18, pp. 2937-2945, 2000.

[7] K. Attiogbe and S. H. Rizkalla, "Response of concrete to sulfuric acid attack," ACI Materials Journal, vol. 85, no. 6, pp. 481-488, 1988.

[8] L. H. Kong and G. James, "Concrete deterioration due to acid precipitation," ACI Materials Journal, vol. 84, no. 2, pp. 110 116, 1987.

[9] N. I. Fattuhi and B. P. Hughes, "The performance of cement paste and concrete subjected to sulphuric acid attack," Cement and Concrete Research, vol. 18, no. 4, pp. 545-553, 1988.
[10] X. B. Hu, "Analysis for simulation test on acid rain attacking concrete," Journal of the Chinese Ceramic Society, vol. 36, supplement 1, pp. 147-152, 2008 (Chinese).

[11] Y. Z. Zhang, Y. F. Fan, J. L. Liu, and X. X. Cao, "Experimental study on compressive performance of concrete C40 in simulated acid environment," Journal of Building Materials, vol. 13, no. 1, pp. 105-110, 2010.

[12] S. Xie, L. Qi, and D. Zhou, "Investigation of the effects of acid rain on the deterioration of cement concrete using accelerated tests established in laboratory," Atmospheric Environment, vol. 38, no. 27, pp. 4457-4466, 2004.

[13] T. J. Wang, L. S. Jin, Z. K. Li, and K. S. Lam, "A modeling study on acid rain and recommended emission control strategies in China," Atmospheric Environment, vol. 34, no. 26, pp. 44674477, 2000.

[14] H. L. Liu, D. Zhou, and D. S. Xie, "A study on influences of acid rain in Southwest China on concrete," Journal of Harbin Institute of Technology, vol. 29, no. 6, pp. 101-104, 1997.

[15] Code for Communications Ministry of P.R.China, Code for Design of Concrete Structures (GB/T 50010-2002), China Architecture and Building Press, Beijing, China, 2002.

[16] Y. F. Fan, Z. Q. Hu, Y. Z. Zhang, and J. L. Liu, "Deterioration of compressive property of concrete under simulated acid rain environment," Construction and Building Materials, vol. 24, no. 10, pp. 1975-1983, 2010.

[17] D. M. Yan and G. Lin, "Influence of initial static stress on the dynamic properties of concrete," Cement and Concrete Composites, vol. 30, no. 4, pp. 327-333, 2008.

[18] Y. Z. Zhang, Y. H. Zhao, and Y. F. Fan, "A theoretical model for assessing elastic modulus of concrete corroded by acid rain," Engineering Mechanics, vol. 28, no. 2, pp. 175-180, 2011 (Chinese). 

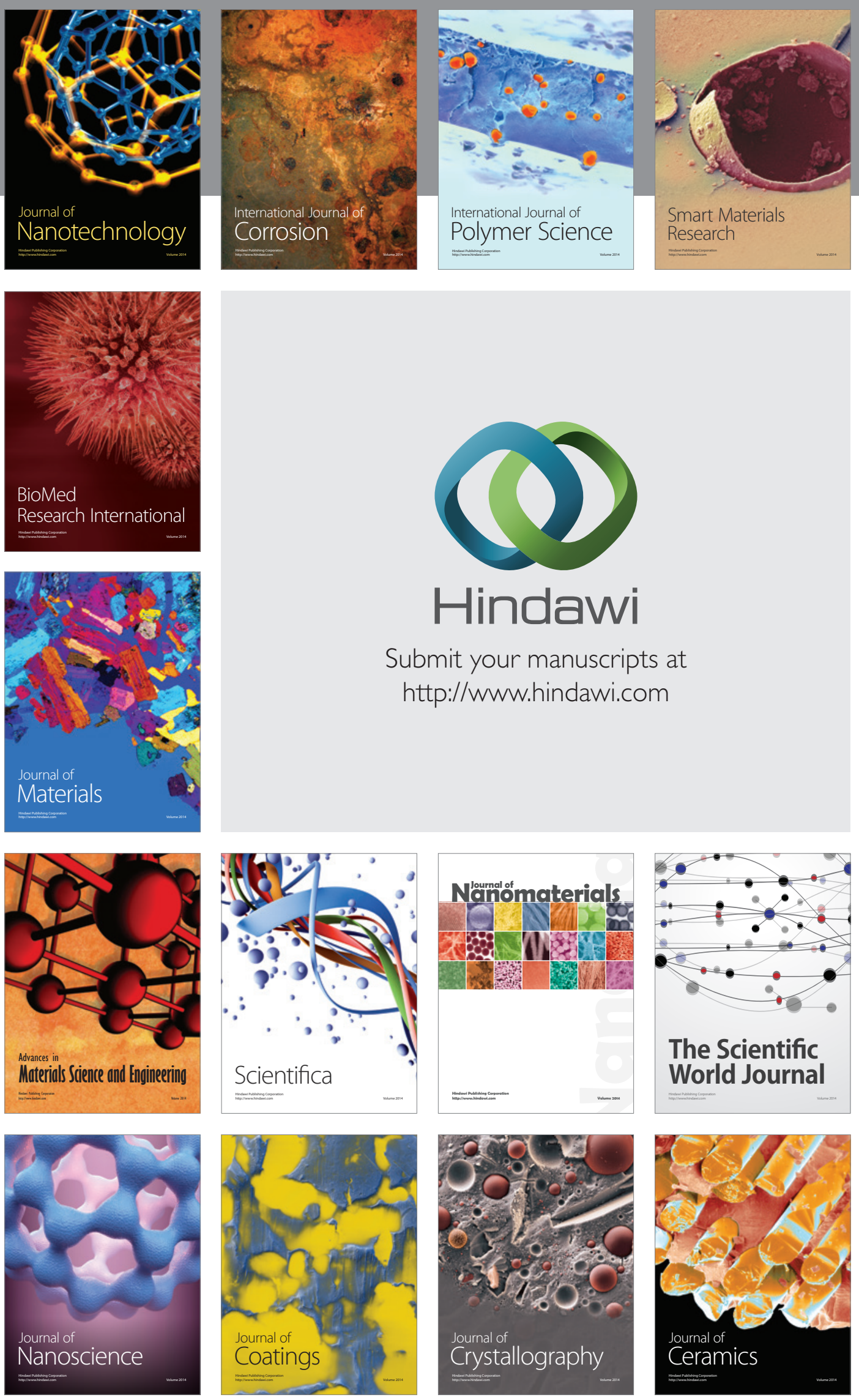

The Scientific World Journal

Submit your manuscripts at

http://www.hindawi.com

\section{World Journal}

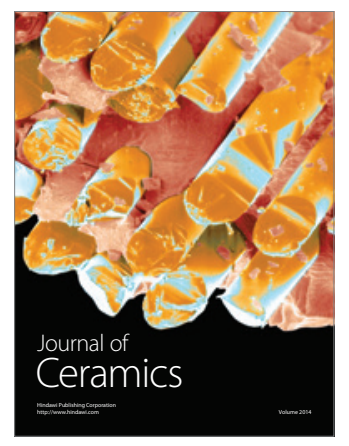

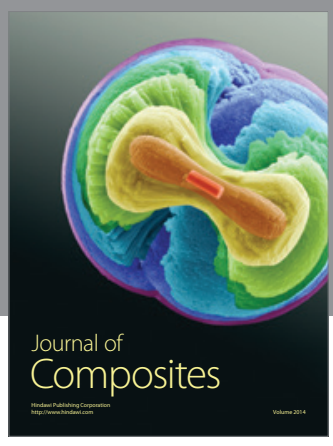
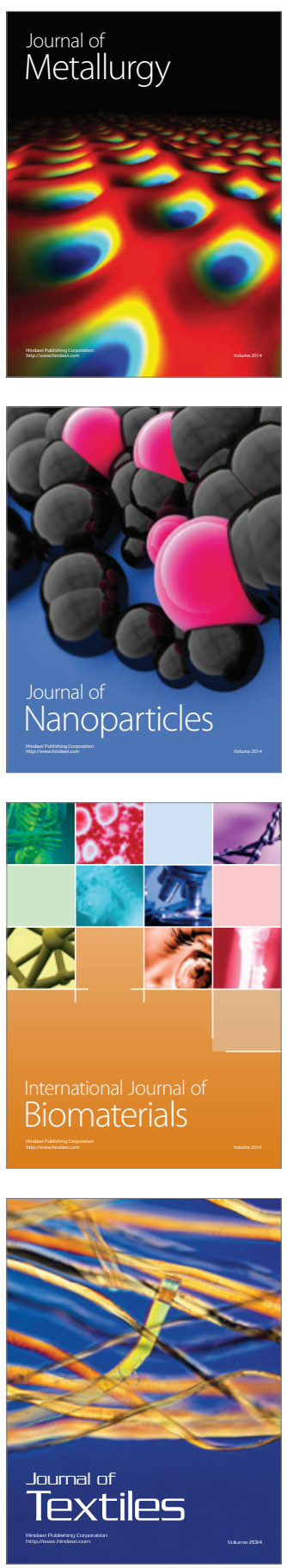